OPEN ACCESS

Edited by:

Maoteng Li,

Huazhong University of Science

and Technology, China

Reviewed by:

Yan Long,

Chinese Academy of Agricultural

Sciences, China

Liezhao Liu,

Southwest University, China

*Correspondence: Rosy Raman

rosy.raman@dpi.nsw.gov.au

Specialty section:

This article was submitted to Crop Science and Horticulture, a section of the journal

Frontiers in Plant Science

Received: 28 July 2017 Accepted: 27 September 2017 Published: 30 November 2017

Citation:

Raman R, Qiu Y, Coombes N,

Song J, Kilian $A$ and Raman $H$ (2017) Molecular Diversity Analysis and Genetic Mapping of Pod Shatter

Resistance Loci in Brassica carinata L. Front. Plant Sci. 8:1765.

doi: 10.3389/fpls.2017.01765

\section{Molecular Diversity Analysis and Genetic Mapping of Pod Shatter Resistance Loci in Brassica carinata L.}

\author{
Rosy Raman ${ }^{1,2 *}$, Yu Qiu' ${ }^{2}$, Neil Coombes ${ }^{2}$, Jie Song ${ }^{3}$, Andrzej Kilian ${ }^{3}$ and Harsh Raman ${ }^{1}$ \\ ${ }^{1}$ Graham Centre for Agricultural Innovation (an alliance between NSW Department of Primary Industries and Charles Sturt \\ University), Wagga Wagga Agricultural Institute, Wagga Wagga, NSW, Australia, ${ }^{2}$ Wagga Wagga Agricultural Institute, NSW \\ Department of Primary Industries, Wagga Wagga, NSW, Australia, ${ }^{3}$ Diversity Arrays Technology Pty. Ltd., University of \\ Canberra, Canberra, ACT, Australia
}

Seed lost due to easy pod dehiscence at maturity (pod shatter) is a major problem in several members of Brassicaceae family. We investigated the level of pod shatter resistance in Ethiopian mustard (Brassica carinata) and identified quantitative trait loci (QTL) for targeted introgression of this trait in Ethiopian mustard and its close relatives of the genus Brassica. A set of 83 accessions of B. carinata, collected from the Australian Grains Genebank, was evaluated for pod shatter resistance based on pod rupture energy (RE). In comparison to $B$. napus (RE $=2.16 \mathrm{~mJ}$ ), $B$. carinata accessions had higher $R E$ values (2.53 to $20.82 \mathrm{~mJ}$ ). A genetic linkage map of an $F_{2}$ population from two contrasting $B$. carinata selections, BC73526 (shatter resistant with high RE) and BC73524 (shatter prone with low RE) comprising 300 individuals, was constructed using a set of 6,464 high quality DArTseq markers and subsequently used for QTL analysis. Genetic analysis of the $F_{2}$ and $F_{2: 3}$ derived lines revealed five statistically significant $Q T L$ $(\mathrm{LOD} \geq 3$ ) that are linked with pod shatter resistance on chromosomes B1, B3, B8, and C5. Herein, we report for the first time, identification of genetic loci associated with pod shatter resistance in $B$. carinata. These characterized accessions would be useful in Brassica breeding programs for introgression of pod shatter resistance alleles in to elite breeding lines. Molecular markers would assist marker-assisted selection for tracing the introgression of resistant alleles. Our results suggest that the value of the germplasm collections can be harnessed through genetic and genomics tools.

Keywords: pod shattering, resistance, genetic mapping, Ethiopian mustard, QTL, molecular markers

\section{INTRODUCTION}

The Ethiopian mustard [syn. Abyssinian mustard; Brassica carinata A. Braun. $(2 \mathrm{n}=4 \times=34)$; genome $\mathrm{B}_{\mathrm{c}} \mathrm{B}_{\mathrm{c}} \mathrm{C}_{\mathrm{c}} \mathrm{C}_{\mathrm{c}}$ ], is an important leafy vegetable and oilseed crop in northeast Africa (Warwick et al., 2006). It is evolved as a result of a few interspecific hybridization events between Brassica nigra (BB genome, $2 \mathrm{n}=2 \times=16$ ) and Brassica oleracea (CC genome, $2 \mathrm{n}=2 \times=18$ ) in Ethiopia. In recent years, this crop is also being utilized for biodiesel production due to its fatty acid composition. In addition, B. carinata harbors several genes for resistance to lodging, diseases, and 
pod shattering; and tolerance to abiotic stresses (Getinet et al., 1996; Taylor et al., 2002; Malik, 2008; Enjalbert et al., 2013; Wei et al., 2016; Sharma et al., 2017), which make it also an ideal candidate for broadening the narrow genetic base of canola - the world's second largest oilseed crop (Cowling, 2007).

Dehiscence of fruiting structures is an orchestrated natural mechanism for seed dispersal and survival of many plant species. In Ethiopian mustard and other members of the Brassicaceae family, a dehiscence zone (DZ) is developed between the two valves and the replum, as the pods mature. The highly differentiated cells in DZ weaken the strength of the pods, leading to seed dispersal at maturity. Pod shattering is a highly undesirable trait for commercial seed production in Brassica crops and causes significant yield losses of up to $70 \%$ in canola (Colton and Potter, 1999). Generally, oilseed Brassicas are 'windrowed' to reduce seed loss due to shattering but this practice is not completely effective (Mongkolporn et al., 2003). Seed losses accelerate further with the prevalence of high wind velocity and extremely high temperatures during the time of harvesting in Australia. One of the foci of many Brassica breeding programs is to develop improved varieties for resistance to pod shattering so the standing crop can be directly harvested with combines without any significant seed loss.

Natural variation for shatter resistance exists in the B. rapa, B. juncea, B. napus, and B. carinata germplasm (Kadkol et al., 1985, 1986b; Prakash and Chopra, 1988; Mongkolporn et al., 2003; Wang et al., 2007; Raman H. et al., 2014; Zhang et al., 2016). However, shatter resistance in B. napus germplasm is insufficient to reduce yield loss under severe weather conditions (Raman H. et al., 2014). B. carinata is reported to be more resistant to seed shattering than B. napus, B. rapa, and, B. juncea (Zhang et al., 2016). Interestingly, $B$. carinata is also known to hybridize with the $\mathrm{A}_{r}$ (B. rapa) and $\mathrm{A}_{\mathrm{n}} \mathrm{C}_{\mathrm{n}}$ (B. napus) genome species and produce viable 'new type' napus plants $\left(A_{n} A_{n} C_{n / c} C_{n / c}\right)$ with diverse $C_{c}$ genome (Navabi et al., 2010; Tian et al., 2010; Banga et al., 2011; Dhaliwal et al., 2017). This knowledge prompted us to characterize genetic variation and identify genetic loci for pod shatter resistance in B. carinata to improve the level of shattering resistance in other Brassica crops, especially in canola.

The testing of germplasm for pod shatter resistance under field conditions is often practiced in breeding programs but it is unreliable and confounded with growing environment. However, the availability of test methods like the random impact test and pendulum test to assess the pod strength have made possible the assessment of germplasm to categorize them into shatter tolerant/susceptible under laboratory conditions (Kadkol et al., 1985; Liu et al., 1994; Hossain et al., 2011). The pendulum test relies on the inherent difference in pod strength measured as 'energy used to rupture pods' [rupture energy (RE)] (Liu et al., 1994).

In B. rapa and B. napus, loci for pod shatter resistance have been delineated using molecular markers (Mongkolporn et al., 2003; Hu et al., 2012; Wen et al., 2013; Raman H. et al., 2014; Liu et al., 2016). For example, Raman H. et al. (2014) reported that several quantitative trait loci (QTL) on chromosomes A03, $\mathrm{A} 09, \mathrm{~A} 10$, and $\mathrm{C} 03$ account for genetic variation in shatter resistance in the doubled haploid (DH) population derived from
BLN2762/Surpass400 as well as in a diverse panel of 181 lines of B. napus. Subsequently, Liu et al. (2016) identified six significant QTL for resistance to pod shatter located on chromosomes A01, A06, A07, A09, C02, and C05 in a diverse panel of 143 B. napus accessions, and bi-parental DH and intermated populations derived from the maternal parent, 'R1' (resistant to pod shattering) and the paternal parent, 'R2' (prone to pod shattering). Both these described studies showed that at least one consistent locus on linkage group A09, which maps in the vicinity of AUXIN RESPONSIVE REGULATOR 18 (ARR18) and MADS-box gene, SHATTERPROOF (BnShp1), controls pod shatter resistance in Australian and Chinese germplasm. Several genes which are involved in a complex regulatory network, such as SHATTERPROOF1 (SHP1); SHATTERPROOF2 (SHP2); FRUITFULL (FUL); INDEHISCENT (IND); ALCALTRAZ (ALC); and REPLUMLESS (RPL), control pod shatter resistance in Arabidopsis thaliana, and other heterologous systems (Ferrandiz et al., 2000; Rajani and Sundaresan, 2001; Roeder et al., 2003; Liljegren et al., 2004, 2009; Chandler et al., 2005; Girin et al., 2010). Some of these genes such as IND and ALC interact with various hormonal pathways involved in auxin, gibberellins and ABA biosynthesis and regulate pod shattering (Sorefan et al., 2009; Arnaud et al., 2010). To our best knowledge, loci associated for natural variation for pod shatter resistance in B. carinata have not been identified yet.

This study aims to (i) characterize genetic variation for pod shatter resistance in B. carinata accessions, (ii) identify the QTL associated with pod strength in an $\mathrm{F}_{2}$ population and a set of 83 accessions, and (iii) determine the physical location of associated $\mathrm{QTL}$ on the B. nigra (BB genome), B. juncea (AB genome), $B$. oleracea (CC genome), and B. napus (AC genome) genomes to identify candidate genes underlying shattering resistance in B. carinata.

\section{MATERIALS AND METHODS}

\section{Plant Materials}

A diversity panel of 200 accessions of Brassica and related species including $B$. carinata (83), B. rapa (90), one accession each of $B$. barrelieri, $B$. deflexa, B. juncea, B. maurorum, B. oxyrrhina, B. ruvo, B. tournefortii, E. sativa, M. longipetala, S. alba, and S. erysimoides, two accessions each of A. thaliana, B. nigra, B. napus, and $S$. arvensis and eight accessions of B. oleracea were obtained from the Australian Grains Genebank, Horsham (Raman R. et al., 2014). In addition, the $F_{2}$ population comprising 300 individuals was developed from a single $\mathrm{F}_{1}$ cross between BC73526 (shatter resistant with high RE) and BC73524 (shattering prone with low RE) to identify the QTL associated with pod shatter resistance. Both parental lines were selected on the basis of their contrasting rupture energy values among 83 accessions of $B$. carinata. Each $F_{2}$ line was selfed to generate $F_{2: 3}$ population to confirm phenotypes.

\section{Evaluation for Pod Shatter Resistance}

The diversity panel comprising 200 accessions was grown in white plastic pots (10 inch diameter, Garden Plastic city, 
Australia) in 2012 and 2013 at the Wagga Wagga Agricultural Institute, New South Wales, Australia. Both trials consisted of a 4 range by 100 row array with two replications. Five plants were grown per pot. Passport data on days to first flowering (first open flower on at least two plants in a pot) were recorded. At maturity, five pods from each plant were collected to evaluate for shatter resistance using the pendulum test as described previously (Raman H. et al., 2014). Pod length from each test sample was measured with a scale excluding the length of 'beak' to adjust the position of the pod when pendulum strikes. In the present study, we only focused on $83 \mathrm{~B}$. carinata accessions for pod shatter resistance (Table $\mathbf{1}$ ).

The two parental lines and their $\mathrm{F}_{2}$ population of 300 plants were grown in 2015 in white plastic pots (10 inch diameter, Garden Plastic city, Australia) under birdcage conditions at the Wagga Wagga Agricultural Institute, New South Wales, Australia. Plants were watered daily, fertilized weekly using inline liquid fertilizers, and protected from aphids. A total of $71 \mathrm{~F}_{2}$ plants showed abnormal phenotypes with flower sterility; these individuals were discarded from genetic analysis. Five pods from $229 \mathrm{~F}_{2}$ plants (normal phenotype) were collected in the $50 \mathrm{~mL}$ tubes containing a silica sachet for further testing of pod rupture energy. Days to flowering was recorded daily for each $\mathrm{F}_{2}$ plant. All $229 \mathrm{~F}_{2}$ plants were enclosed with pollination bags to get pure $\mathrm{F}_{3}$ progenies, while leaving the primary stem out for the natural pod development for shatter testing. Ten $\mathrm{F}_{3}$ plants from $229 \mathrm{~F}_{2}$ families were grown in 2016 in a 20 row $\times 12$ column array design including nine controls and two parents at Wagga Wagga. Five pods were collected per $\mathrm{F}_{3}$ plant. For validation, $58 \mathrm{~F}_{2: 3}$ families (29 high RE and 29 low RE) and parents were tested with pendulum test as described earlier (Raman H. et al., 2014).

\section{Microscopic Analysis of Pod Anatomy}

Anatomical features of pod DZ were observed in 30 random $\mathrm{F}_{2}$ plants and five $\mathrm{F}_{2: 3}$ progenies from $20 \mathrm{~F}_{2}$ plants selected on the basis of their rupture energy (10 each with low RE and high RE). Pods were collected at 35-40 days after anthesis. Hand sections were prepared from one $\mathrm{cm}$ from the pedicel end of the pod. Fresh sections were observed for autofluorescence using a fluorescence microscope at the Charles Sturt University, Wagga Wagga. Photographs were taken using a Zeiss Axiphot microscope fitted with a Sony Cyber-shot digital camera.

\section{Statistical Analyses of Phenotypic Data}

The rupture energy data of an $\mathrm{F}_{2}$ population and of a set of 83 diversity lines were square-root transformed to normalize and further analyzed using ASREML in R. Genotype was considered as a fixed effect and environment as random effects. The estimated means for each genotype were used for further genome-wide association analysis. The correlation between rupture energy in 2012 and 2013 was calculated using Pearson's correlation coefficient. $\mathrm{RE}$ of five pods of each $\mathrm{F}_{2}$ plant was averaged and used for QTL analysis.

\section{DNA Isolation and Genotyping}

Young leaf tissue of the field grown plants was collected for DNA isolation. Tissue were ground in liquid nitrogen and extracted using a method described in Raman et al. (2005). The diversity panel of $83 \mathrm{~B}$. carinata accessions and the $\mathrm{F}_{2}$ population comprising 300 lines were genotyped with the genotyping-bysequencing based DArTseq marker approach (Raman H. et al., 2014) at the DArT P/L, University of Canberra, Australia.

\section{Genetic Relatedness and Population Structure}

In order to determine molecular diversity in B. carinata, we genotyped 83 accessions with high-quality DArTseq markers having call rate of $\geq 90 \%, \leq 5 \%$ of missing data and minor allele frequency (MAF) of $>0.05$. Hierarchical cluster analysis based on Euclidian distance was conducted using the software, PRIMER 6 (Clarke and Gorley, 2006). Principal coordinate analysis was performed to understand the global diversity among accessions. Bayesian clustering was performed to infer the number of subpopulations among 83 accessions using the software package STRUCTURE v 2.3.4 (Pritchard et al., 2000 ). The program was run using admixture model with correlated allele frequencies. The presumed sub-population number $(k)$ was set from 1 to 5 . Ten runs for each $k$ were performed with 20,000 burn in period and 50,000 Markov Chain Monte Carlo iterations per run, with no prior information on the origin of individuals. The best $k$ value was determined by using the (i) logarithm likelihood for each $k[\mathrm{~L}(k)]$, (ii) an ad hoc quantity $(\Delta k)$ according to Rosenberg et al. (2001) and $\Delta k$ method described by Evanno et al. (2005), respectively. Genotypes were classified into subpopulations based on their membership coefficients estimated in STRUCTURE.

\section{Map Construction and QTL Identification for Pod Shatter Resistance}

The linkage map of $\mathrm{F}_{2}$ population was constructed using DArT P/L's OCD MAPPING program (Petroli et al., 2012). Markers were clustered into linkage groups according to the method described by Wu et al. (2008). Markers with identical genotypes are placed in redundant bins, and the resulting markers/bins within each linkage group were ordered using the traveling salesman path solver program Concorde (Applegate et al., 2006). The linkage map was constructed for each parent by combining the relevant in silico DArT and SNP markers. A linkage map was chosen to be seed map and then a consensus map was constructed using the markers in common for the complete $\mathrm{F}_{2}$ population.

Two QTL mapping strategies implemented in software packages, GAPIT in the R (Lipka et al., 2012) and SVS (Golden Helix, Bozeman, MT, United States) were used to identify loci associated with pod shatter tolerance. For GAPIT analysis, we did not correct population structure using principal components in the $F_{2}$ mapping population. Linear marker regression analysis was performed to determine trait-marker associations in the SVS package. The same approach was also followed to reveal the genome-wide association between DArTseq markers and rupture energy among 83 accessions. For GWAS, we selected a set of 54,034 high quality markers which were genotyped across all accessions. To control spurious trait-marker associations, the first 10 eigenvectors (principal components) were calculated in the SVS package. Cryptic relatedness due to ancestry by descent was 
TABLE 1 | Natural variation for pod shatter resistance in Brassica carinata accessions grown under birdcage conditions in 2012 and 2013.

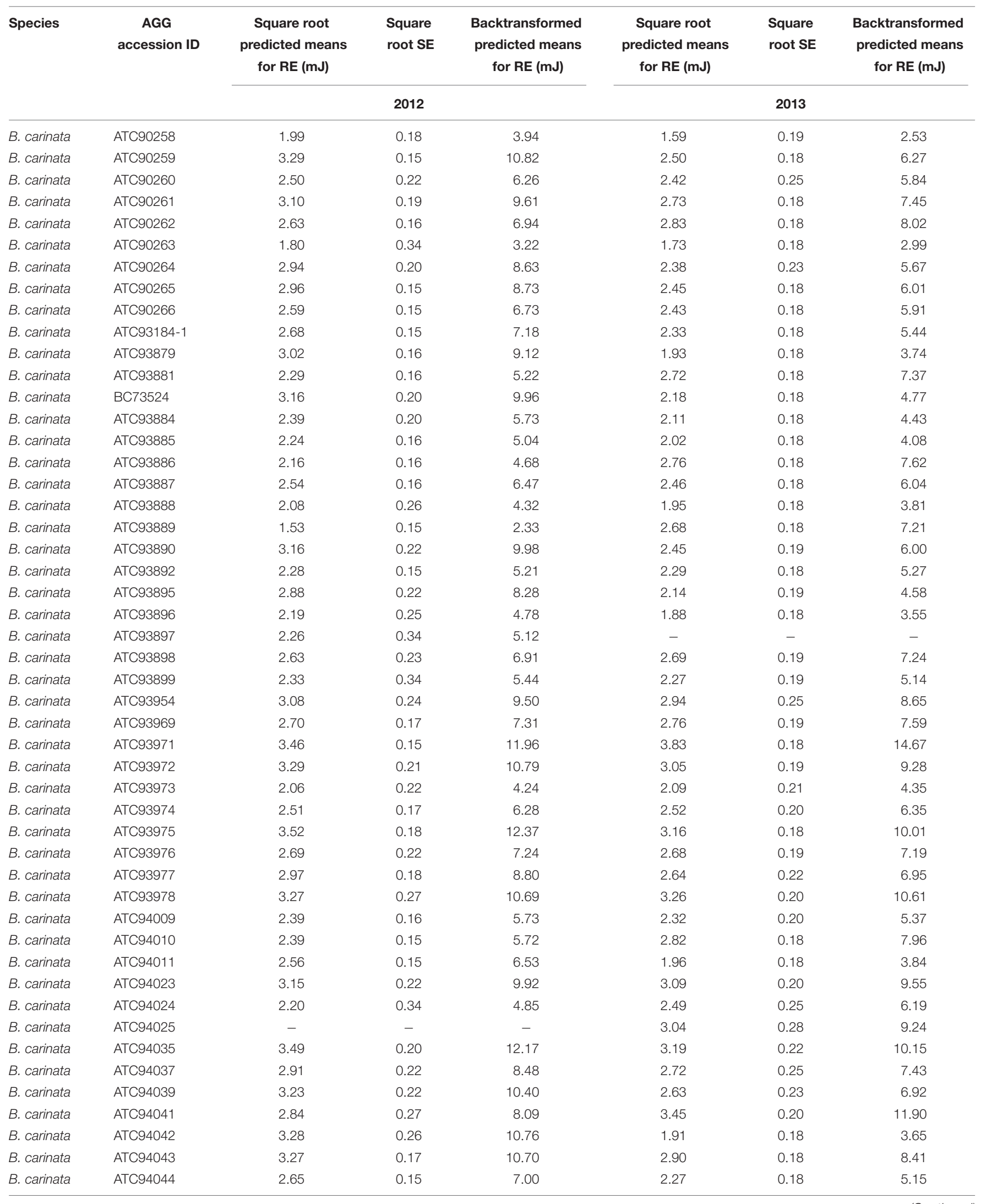


TABLE 1 | Continued

\begin{tabular}{|c|c|c|c|c|c|c|c|}
\hline \multirow[t]{2}{*}{ Species } & \multirow[t]{2}{*}{$\begin{array}{c}\text { AGG } \\
\text { accession ID }\end{array}$} & \multirow[t]{2}{*}{$\begin{array}{c}\text { Square root } \\
\text { predicted means } \\
\text { for } R E(m J)\end{array}$} & \multirow{2}{*}{$\begin{array}{c}\text { Square } \\
\text { root SE } \\
2012\end{array}$} & \multirow[t]{2}{*}{$\begin{array}{l}\text { Backtransformed } \\
\text { predicted means } \\
\text { for RE (mJ) }\end{array}$} & \multirow[t]{2}{*}{$\begin{array}{c}\text { Square root } \\
\text { predicted means } \\
\text { for RE (mJ) }\end{array}$} & \multirow{2}{*}{$\begin{array}{c}\text { Square } \\
\text { root SE } \\
2013\end{array}$} & \multirow[t]{2}{*}{$\begin{array}{c}\text { Backtransformed } \\
\text { predicted means } \\
\text { for RE }(\mathrm{mJ})\end{array}$} \\
\hline & & & & & & & \\
\hline B. carinata & ATC94045 & 3.29 & 0.18 & 10.80 & 3.02 & 0.18 & 9.12 \\
\hline B. carinata & ATC94046 & 3.10 & 0.16 & 9.63 & 3.69 & 0.18 & 13.63 \\
\hline B. carinata & ATC94047 & 3.54 & 0.15 & 12.50 & 3.20 & 0.19 & 10.26 \\
\hline B. carinata & ATC94048 & 2.66 & 0.16 & 7.09 & 2.64 & 0.18 & 6.97 \\
\hline B. carinata & ATC94049 & 2.98 & 0.34 & 8.91 & 2.53 & 0.18 & 6.38 \\
\hline B. carinata & ATC94050 & 2.14 & 0.34 & 4.58 & 2.41 & 0.20 & 5.80 \\
\hline B. carinata & ATC94109 & 2.96 & 0.19 & 8.79 & 3.12 & 0.21 & 9.72 \\
\hline B. carinata & ATC94111 & 3.06 & 0.20 & 9.37 & 2.01 & 0.18 & 4.03 \\
\hline B. carinata & ATC94113 & 2.77 & 0.20 & 7.70 & 3.02 & 0.25 & 9.14 \\
\hline B. carinata & ATC94114 & 3.32 & 0.21 & 11.03 & 2.41 & 0.28 & 5.83 \\
\hline B. carinata & ATC94116 & 2.41 & 0.27 & 5.83 & 2.56 & 0.40 & 6.56 \\
\hline B. carinata & ATC94117 & 2.26 & 0.22 & 5.12 & 2.30 & 0.18 & 5.31 \\
\hline B. carinata & ATC94119 & 2.85 & 0.17 & 8.11 & 2.89 & 0.19 & 8.38 \\
\hline B. carinata & ATC94120 & 1.76 & 0.18 & 3.08 & 1.96 & 0.19 & 3.84 \\
\hline B. carinata & ATC94125 & 2.28 & 0.16 & 5.21 & 2.58 & 0.18 & 6.66 \\
\hline B. carinata & ATC94126 & 4.01 & 0.17 & 16.11 & 4.44 & 0.20 & 19.75 \\
\hline B. carinata & ATC94134 & 2.67 & 0.15 & 7.15 & 2.15 & 0.18 & 4.64 \\
\hline B. carinata & ATC94135 & 2.41 & 0.15 & 5.82 & 1.88 & 0.19 & 3.55 \\
\hline B. carinata & ATC94137 & 2.46 & 0.17 & 6.05 & 1.80 & 0.18 & 3.24 \\
\hline B. carinata & ATC94138 & 2.06 & 0.21 & 4.26 & 2.51 & 0.18 & 6.30 \\
\hline B. carinata & ATC94139 & 2.90 & 0.16 & 8.43 & 1.89 & 0.18 & 3.56 \\
\hline B. carinata & ATC94192 & 1.91 & 0.24 & 3.64 & 2.05 & 0.19 & 4.22 \\
\hline B. carinata & ATC94409 & 2.08 & 0.38 & 4.33 & 2.70 & 0.22 & 7.30 \\
\hline B. carinata & ATC94411 & 2.66 & 0.34 & 7.08 & 2.34 & 0.21 & 5.47 \\
\hline B. carinata & ATC94416 & 2.82 & 0.26 & 7.93 & 2.45 & 0.22 & 6.01 \\
\hline B. carinata & ATC94427 & 2.15 & 0.34 & 4.60 & - & - & - \\
\hline B. carinata & ATC94429 & 3.24 & 0.22 & 10.51 & 2.68 & 0.18 & 7.17 \\
\hline B. carinata & ATC94455 & 2.27 & 0.18 & 5.15 & 2.22 & 0.18 & 4.91 \\
\hline B. carinata & ATC94457 & 4.50 & 0.17 & 20.26 & 4.56 & 0.19 & 20.82 \\
\hline B. carinata & ATC94458 & 4.22 & 0.15 & 17.83 & 4.55 & 0.18 & 20.74 \\
\hline B. carinata & ATC94461 & 2.46 & 0.18 & 6.04 & 2.45 & 0.20 & 5.99 \\
\hline B. carinata & ATC94463 & 2.39 & 0.22 & 5.73 & 1.89 & 0.23 & 3.58 \\
\hline B. carinata & ATC95065 & 2.60 & 0.19 & 6.74 & 2.59 & 0.20 & 6.70 \\
\hline B. carinata & ATC95199 & 2.17 & 0.15 & 4.72 & 2.16 & 0.18 & 4.67 \\
\hline B. napus & BLN2762 & 1.68 & 0.16 & 2.82 & 1.47 & 0.18 & 2.16 \\
\hline
\end{tabular}

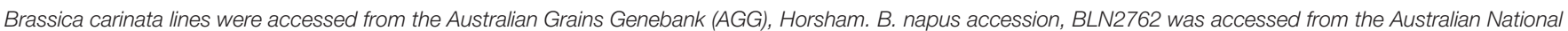

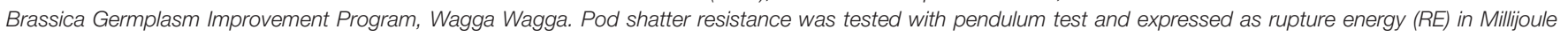
$(\mathrm{mJ})$. RE values were initially square rooted and then back transformed.

SE and -, represent to standard error (SE) and missing data, respectively.

controlled with the Identity-by-Decent matrix (K matrix). The Mixed Linear Model (Price, 2006; Yu et al., 2006) adjusted with K-matrix and population structure matrix with PC1 - PC10 was used to test the trait-marker associations in the SVS package. The $p$-values were adjusted to control the false discovery rate (FDR) of $5 \%$. The significance threshold was determined by applying Bonferroni correction $[p=0.05 / 6464$ (total of markers mapped): $\left.7.73515 \mathrm{E}_{-06}\right]$. Trait-markers with significance $\leq \log (10) p$ of 5.11153 were 'declared' as true associations for pod shatter resistance in an $F_{2}$ population. Manhattan plots were generated in the SVS package.

\section{Alignment of Markers with the Brassica Reference Genomes}

The physical map positions of significant markers associated with pod shatter resistance were determined using the reference B. nigra, B. oleracea, B. juncea, and B. napus genomes by BlastN (Altschul et al., 1990) searches, as detailed in Raman H. et al. (2014). The physical positions of pod shatter resistance genes in A. thaliana (accessed from TAIR ${ }^{1}$ ) were also determined

\footnotetext{
${ }^{1}$ https://www.arabidopsis.org
} 

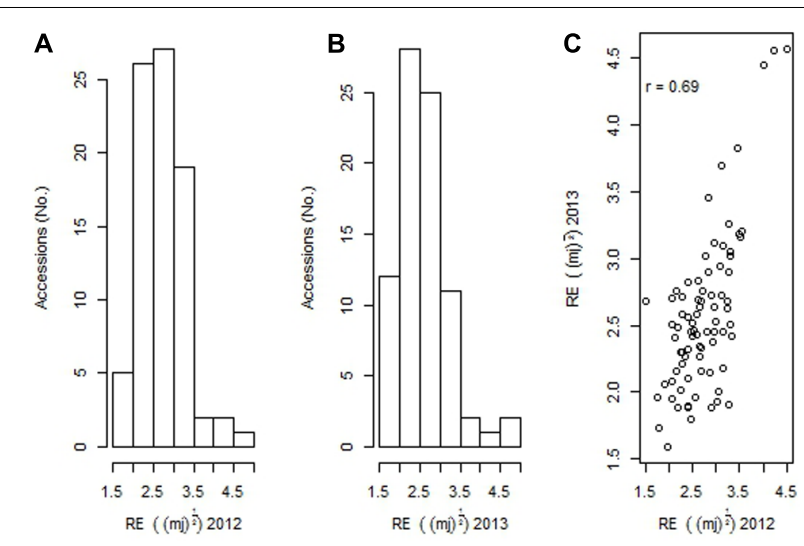

FIGURE 1 | (A) Natural variation for pod shatter resistance in 83 accessions of Brassica carinata evaluated under 2012 and (B) 2013 environments, and (C) correlation of rupture energy (RE) scores of 83 accessions evaluated under 2012 and 2013 environments. Pod shatter resistance was measured with pendulum test as RE. RE presented for different accessions are square root transformed.

by searching sequence identities with the reference genomes. The top blast significant hits $\left(\geq \mathrm{E}^{-10}\right)$ were considered to infer the putative physical positions of markers/candidate genes on the reference genomes, while blast hits to multiple loci with the same top $\mathrm{E}$ value were considered to be unmapped onto the reference genome.

\section{RESULTS}

\section{Phenotypic Variation for Pod Shatter Resistance in B. carinata Accessions}

There were significant differences $(p<0.001)$ within the 83 $B$. carinata accessions tested with respect to pod rupture energy that ranged from 1.52 to $4.5 \mathrm{~mJ}$ in 2012, and 1.6 and $4.6 \mathrm{~mJ}$ in 2013 (Figures 1A,B). A positive strong correlation $(r=0.69)$ among accessions evaluated across both the 2012 and 2013 growing environments was observed, indicating that $\mathrm{RE}$ is genetically controlled (Figure 1C). Three B. carinata accessions, ATC94126, ATC94457, and ATC94458 had 9.14 to 9.63 times higher RE compared to the B. napus control genotype, BLN2762 (Table 1).

\section{Genetic Diversity and Population Structure}

A set of 54,037 high quality DArTseq markers with call rates of $>90 \%$ and a reproducibility of $>95 \%$ were selected for genetic diversity and population structure analyses to determine whether shatter resistant sources are genetically diverse (Table 1). Hierarchical cluster analysis based on the Euclidean distance revealed five distinct groups at $60 \%$ similarity (Figure 2A). The cluster I was the largest with 75 accessions, followed by three accessions in cluster II (ATC94120, ATC93973, and ATC94192) and cluster IV (ATC90258, ATC94011, and ATC93888). Both cluster III (ATC94409), and cluster V (ATC94109) contained only one accession (Figure 2A). The overall genetic diversity among accessions was assessed with PCO analysis (Figure 2B), which revealed similar clustering. There were four clear groups with the majority of the accessions in cluster I. The first three coordinates $(\mathrm{PC} 1=15.9 \%, \mathrm{PC} 2=5.3 \%$, and $\mathrm{PC} 3=4.3 \%)$ accounted a total of $25.39 \%$ of the genetic variation (Figure 2B), suggesting a weak population structure. The Bayesian - based clustering analysis using the maximum likelihood distribution $\operatorname{LnP}(\mathrm{D})$ of 83 accessions identified two sub-populations as shown in Figure 2C. The Wilcoxon test also revealed the presence of two subpopulations. Seventy nine accessions were in sub-population I and four accessions were in sub-population II. The STRUCTURE analysis supported the results of cluster analysis; all 83 accessions were grouped in two clusters at 90\% similarity (Figure 2A).

\section{Genetic Variation and Inheritance for Pod Shatter Resistance}

Based on the pod shatter resistance (RE) scores, two single plant selections were made from accessions BC73526 (high $\mathrm{RE}$ ) and $\mathrm{BC} 73524$ (low $\mathrm{RE}$ ) to generate an $\mathrm{F}_{2}$ population, representing cluster I (Figure 2A). Both parental lines of the $\mathrm{F}_{2}$ mapping population from the cross, BC73524/BC73526 differed significantly from each other with respect to pod shatter resistance; the shatter prone, maternal parent (BC73524) had the lower RE of $2.2 \mathrm{~mJ}^{(1 / 2)}(4.8 \mathrm{~mJ})$ and the resistant, paternal parent (BC73526) had the higher RE of $4.4 \mathrm{~mJ}^{(1 / 2)}(19.8 \mathrm{~mJ}$; Table 1). The $\mathrm{F}_{2}$ population showed a continuous distribution of $\mathrm{RE}$ scores, ranging from 2.2 to $4.7 \mathrm{~mJ}^{(1 / 2)}$ with the mean score of $2.71 \mathrm{~mJ}^{(1 / 2)}$ (Figure 3). This was typical for quantitative traits such as pod shattering resistance. In order to validate these $F_{2} R E$ scores, we evaluated the $\mathrm{F}_{2: 3}$ progenies (Supplementary Table $\mathrm{S} 1$ ). Our results showed that there was a strong positive correlation $\left(r=0.83\right.$ ) between $\mathrm{RE}$ scores of $\mathrm{F}_{2}$ plants and their $\mathrm{F}_{2}: 3$ progenies, suggesting that phenotypic scores in $\mathrm{F}_{2}$ were accurate.

\section{Multiple Genes Control Pod Shatter Resistance in $B$. carinata}

A total of 6,464 markers that showed polymorphism between the parents, and segregated in the complete set of $F_{2}$ population (300 lines) were selected for the genetic linkage map construction (Supplementary Table S1). All of the mapped markers were assigned to the 17 linkage groups, equivalent of haploid genome of $B$. carinata. Of them, 4,981 marker loci were located on the 8 linkage groups of $\mathrm{B}_{\mathrm{c}}$ subgenome and 1,483 loci were on the 9 linkage groups of $\mathrm{C}_{\mathrm{c}}$ subgenome, covering a total genetic distance of $1622.82 \mathrm{cM}$ (Table 2). The marker density ranged from 1.07 (C4) to 7.35 (B01) with an average density of $3.98 \mathrm{cM}$. Chromosome C5 had the least number of markers (78) as compared to B4 (881). This genetic linkage map was further used for the QTL identification.

We identified five significant QTL (LOD $=3$ ) associated with pod shatter resistance, Qpsr.wwai-B1a, Qpsr.wwaiB1b, Qpsr.wwai-B3, Qpsr.wwai-B8, and Qpsr.wwai-C5 in the BC73524/BC73526 population (Table 3, Figure 4A and Supplementary Table S1). Two QTL; Qpsr.wwai-B1a tagged with the in silico DArT marker 5863583, and Qpsr.wwai-B1b 


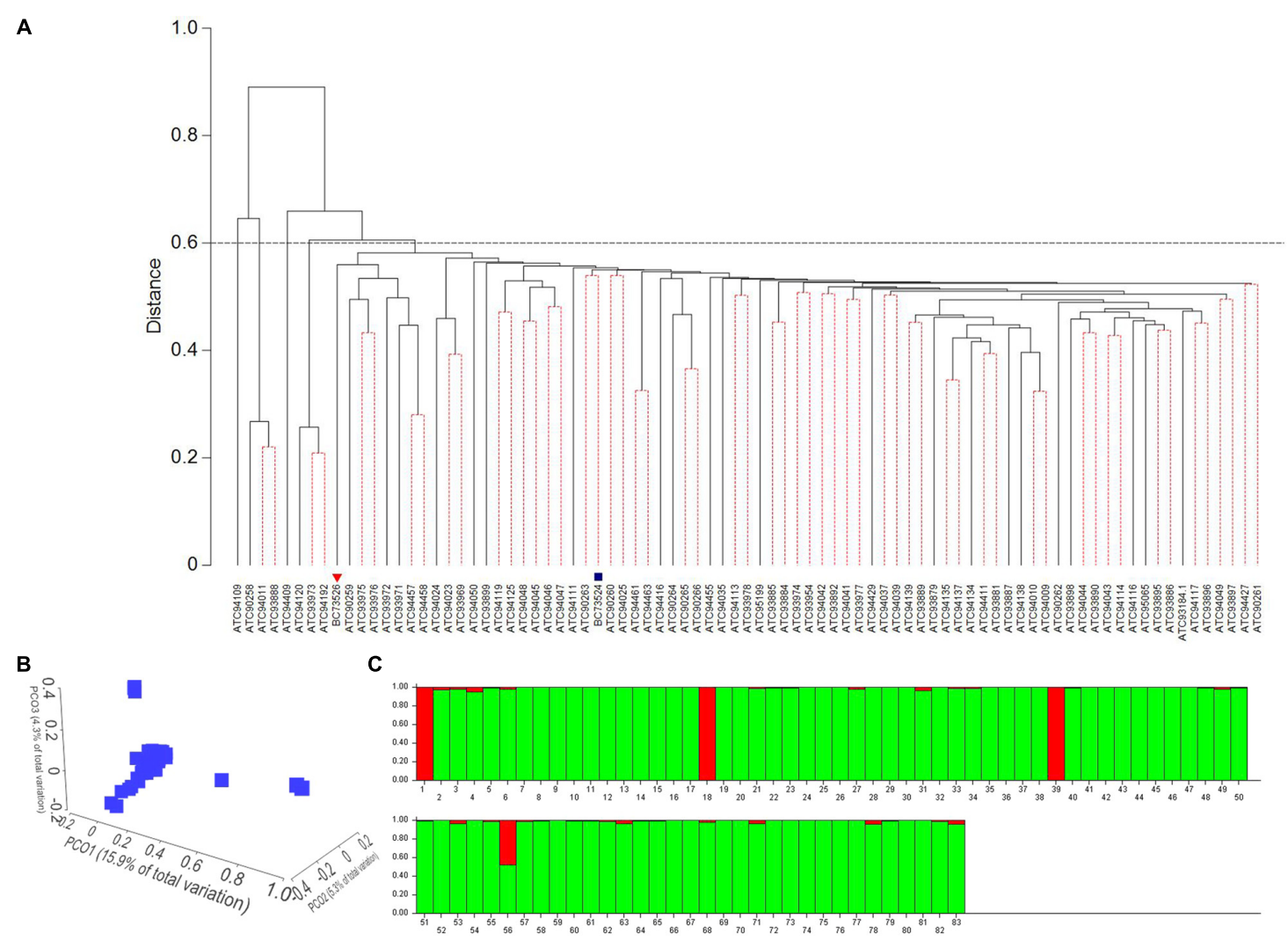

FIGURE 2 | Molecular diversity among B. carinata accessions revealed by 54,034 DArTseq markers. (A) Dendrogram of 83 B. carinata accessions based on Euclidean distance. A total of 1,000 bootstraps were performed. Clusters with dotted lines were non-significant at the $5 \%$ level of significance. Parental lines, BC73526 and BC732524 are markers with inverted triangle ( $\mathbf{v})$ and square $(\mathbf{\square})$, respectively. (B) A 3D plots of the first three principal coordinates (PCO) of (PCO1, PCO2, and PCO3) showing distribution of the $B$. carinata accessions. The proportion of variation by these axes is given in parentheses. (C) Population structure of $B$ carinata accessions by STURUCTURE. Each accession is represented by a vertical bar (labeled as 1 to 83 , representing different accessions; detailed in Table 1). Red and light green color bars represent to two subpopulations I and II, respectively. Number of subpopulations were determined on $\Delta k$ [the rate of change of $\mathrm{LnP}(\mathrm{D})]$ as shown in Supplementary Figure $\mathbf{S 1 .}$

tagged with DArTseq-SNP marker 5858104|F| 0-14:A > T, were located $7.4 \mathrm{cM}$ apart on chromosome B1. Other three QTL, Qpsr.wwai-B3, Qpsr.wwai-B8, and Qpsr.wwai-C5 were identified on chromosomes B3, B8, and $\mathrm{C} 5$, respectively (Table 3). Of these, Qpsr.wwai-B1b accounted for the maximum (5.27\%) of the phenotypic variation and the Qpsr.wwai-C5 accounted for the least (3.71\%). All five QTL explained a total of $23.73 \%$ of the phenotypic variation for RE. The shatter resistant parent, BC73526 contributed the favorable allele as envisaged by pod strength, and thus reduced pod shattering in progenies. DArTseq markers were assigned the physical positions on $B$. carinata genome, by comparing their sequence identities with the reference genomes of $B$. nigra, B. juncea, B. oleracea, and B. napus. Our results showed that the Qpsr.wwai-B1a, qPSR.wwai-B1b, Qpsr.wwai-B3, Qpsr.wwai-B8, and Qpsr.wwai$C 5$ were located to the pseudomolecules of B1, B3, B8, and C5, respectively (Supplementary Figure S2 and Table S2).

To establish whether pod length relates to pod shattering, we mapped QTL associated with pod length in the $\mathrm{F}_{2}$ population. Our results showed that one significant marker, 5859132|F| 0-7:T $>$ G at QTL (LOD = 3.55) was associated with pod

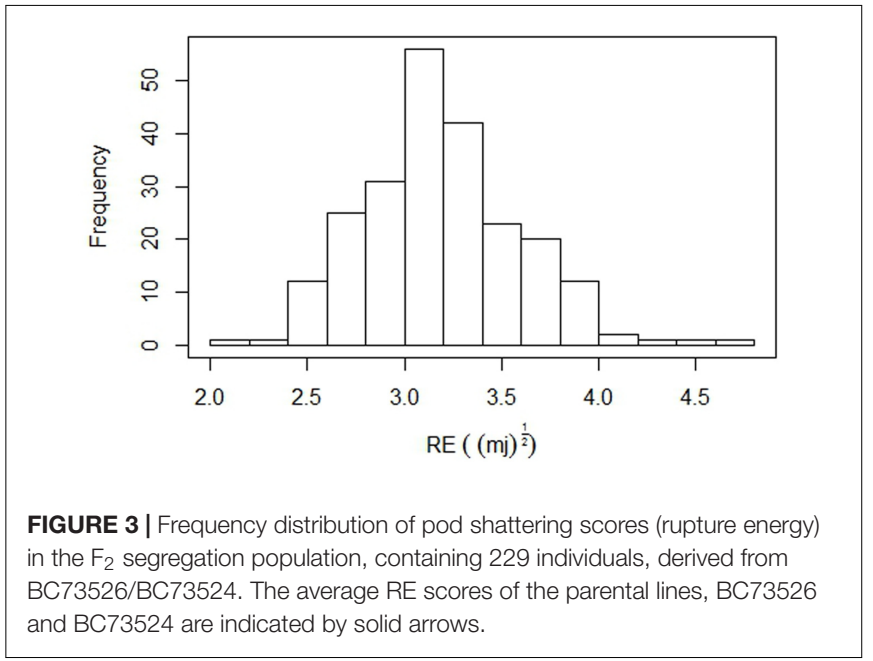

length in the $\mathrm{F}_{2}$ population (Figures 3, 4B, and Supplementary Tables S2, S3). This QTL was identified on chromosome B8 
TABLE 2 | Summary of segregating markers and their coverage on the linkage genetic map of the $\mathrm{F}_{2}$ population derived from the BC73524/BC73526 of B. carinata.

\begin{tabular}{|c|c|c|c|}
\hline Chromosome & $\begin{array}{l}\text { Mapped } \\
\text { markers }\end{array}$ & $\begin{array}{c}\text { Map length } \\
\text { (cM) }\end{array}$ & $\begin{array}{c}\text { Average } \\
\text { marker } \\
\text { density/cM }\end{array}$ \\
\hline B1 & 835 & 113.61 & 7.35 \\
\hline B2 & 634 & 128.87 & 4.92 \\
\hline B3 & 591 & 117.05 & 5.05 \\
\hline B4 & 881 & 148.70 & 5.92 \\
\hline B5 & 667 & 130.15 & 5.12 \\
\hline B6 & 386 & 90.28 & 4.28 \\
\hline B7 & 445 & 93.27 & 4.77 \\
\hline B8 & 542 & 141.86 & 3.82 \\
\hline Subtotal of Bc subgenome & 4981 & 963.80 & 5.17 \\
\hline C1 & 120 & 68.19 & 1.76 \\
\hline C2 & 113 & 36.09 & 3.13 \\
\hline C3 & 348 & 109.79 & 3.17 \\
\hline C4 & 94 & 88.12 & 1.07 \\
\hline C5 & 78 & 26.41 & 2.95 \\
\hline C6 & 212 & 71.98 & 2.95 \\
\hline $\mathrm{C7}$ & 130 & 65.11 & 2.00 \\
\hline $\mathrm{C} 8$ & 120 & 82.94 & 1.45 \\
\hline C9 & 268 & 110.40 & 2.43 \\
\hline Subtotal of the Cc subgenome & 1483 & 659.04 & 2.25 \\
\hline Total of the $\mathrm{B}_{\mathrm{C}} \mathrm{C}_{\mathrm{c}}$ genome & 6464 & 1622.842 & \\
\hline Mean & 380.23 & 95.46 & 3.98 \\
\hline
\end{tabular}

LG were assigned to eight chromosomes of the $B_{C}$ subgenome and nine chromosomes of the $C_{C}$ subgenome of $B$. carinata on the basis of their physical map locations on the reference genomes of B. nigra, B. juncea $\mathrm{CV}$. Tumida (for the $B$ subgenome), B. oleracea (T1000) and B. napus CV. Darmor (for the C subgenome).

and mapped $1 \mathrm{cM}$ apart from the pod shatter resistance QTL, Qpsr.wwai-B8. Two other markers, 5832583 and 5863583 on chromosome B1 also showed association with pod length (LOD scores of 2.7 to 2.9, Supplementary Table S3).

GWAS analysis using 54,034 markers based polymorphisms was performed to verify the alleles for pod shatter resistance in diverse B. carinata accessions Although, we used a small number of accessions for this analysis, we found 19 statistically significant SNP associations between markers and pod shatter resistance (RE scores) based on the Bonferroni corrected threshold $-\log 10(p)=9.25292 \mathrm{E}^{-07}$ (Supplementary Table S3). By controlling type 1 error using kinship coefficients (IBS) and first 10 principal components at least 16 consistent significant associations were identified across both 2012 and 2013 trials with LOD score of $\leq 5.35$ (Supplementary Tables S3, S4).

\section{Physical Mapping of Significant QTL and Alignment with Brassica Reference Genomes}

Of 6464 DArTseq markers mapped, the chromosomal positions of 5,080 markers could be linked with the pseudomolecule positions to the published genome sequences of $B$. oleracea, B. napus, B. juncea, and B. nigra (Supplementary Table S1). We also anchored several scaffolds which have been unmapped yet to the pseudomolecules of $B$. juncea genome assembly in an $\mathrm{F}_{2}$ population. Furthermore, marker sequences targeting QTL were aligned with the sequenced reference $\mathrm{B}, \mathrm{C}$ and $\mathrm{AC}$ genomes and physical intervals harboring candidate genes for pod shatter resistance. Of the seven pod shatter resistance genes of $A$. thaliana searched, FUL - a MADS box gene negatively regulated by APETALA1 (TAIR ID: AT5G60910.1), was located $63.1 \mathrm{~kb}$ away from the significant SNP marker, 5863583 on chromosome 1B (Table 3). Other candidate genes were located 0.4 to $8.3-\mathrm{Mbp}$ apart from corresponding QTL regions in the $\mathrm{F}_{2}$ population (Supplementary Tables S4, S5). We identified 40 GWAS SNP associations ( $\mathrm{LOD} \leq 3)$ in the proximity $(5.1 \mathrm{~kb}$ to $16 \mathrm{Mbp})$ of genes controlling pod shattering in A. thaliana. Of them, three orthologs of FUL were located on chromosome B1 $(5.1 \mathrm{~kb})$, B6 (97.4 kb) and on the LFLV01001230.1scaffold_28.1 of the reference genome of $B$. nigra $(34.69 \mathrm{~kb})$, while two orthologs of IND were located on chromosome B1 (53.69 kb) and B2 (96.77 kb). One ortholog of SHP2 was also identified within $77 \mathrm{~kb}$ region of chromosome $\mathrm{B} 5$ corresponding to SNP association with 100067358|F| 0-31:T > C marker (Supplementary Table S5).

\section{Pod Shatter Resistance Is Related with Pod Dehiscence Zone Differentiation in B. carinata}

Pod structure was observed (40 days after anthesis) under a fluorescence microscope to determine any link between the pod DZ differentiations and shatter resistance in B. carinata. The anatomical feature of parents displayed a distinctive difference in the valve margin formation (Figure 5). The shatter prone parent, BC73524 had the well-developed DZ comprising thin walled parenchymatous cells (Figure 5a) compared to the shatter resistant parent, BC73526 (Figure 5b). Thirty randomly selected $\mathrm{F}_{2}$ plants exhibited a varied level of $\mathrm{DZ}$ development pattern (Figures 5d-i). For example, there was either clear DZ along the whole valve margin (Figure 5e), similar to shatter prone parent (Figure 5a); loss of DZ proximal to the main vascular bundle (mv) as well as near the outer part of the replum (Figure 5d), similar to the shatter tolerant parent (Figure 5c); and DZ proximal to the main vascular bundle (mv) but did not extend near the outer part of the replum (Figure 5h). In B. napus, a well-developed DZ was clearly evident (Figure 5c) similar to the shatter prone B. carinata parent, BC73524.

\section{DISCUSSION}

Considering the commercial value of oilseed Brassica crops (B. napus, B. rapa, and B. juncea) worldwide, genetic improvement for pod shatter resistance is of paramount importance to reduce unwanted losses. Despite of limited genetic diversity in B. carinata germplasm (Jiang et al., 2007; Guo et al., 2012), several accessions were found to be useful in uncovering genetic variation for resistance to pod shatter (Table 1). For example, we found three accessions which had more than nine times higher pod $\mathrm{RE}$ as compared to the B. napus control genotype, BLN2762. Genetic variation in these accessions could 


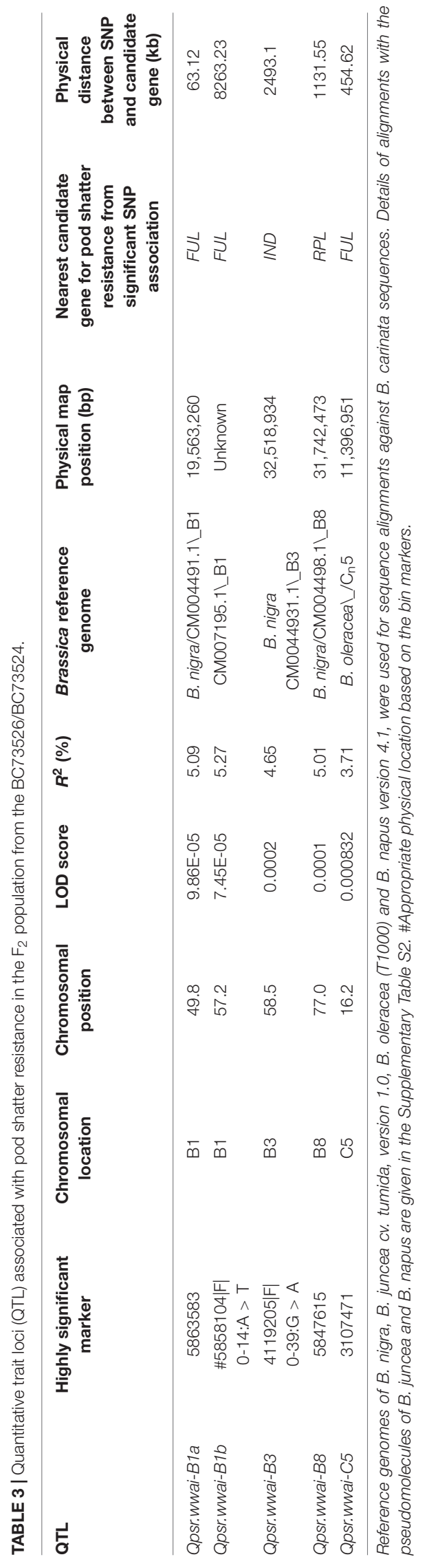

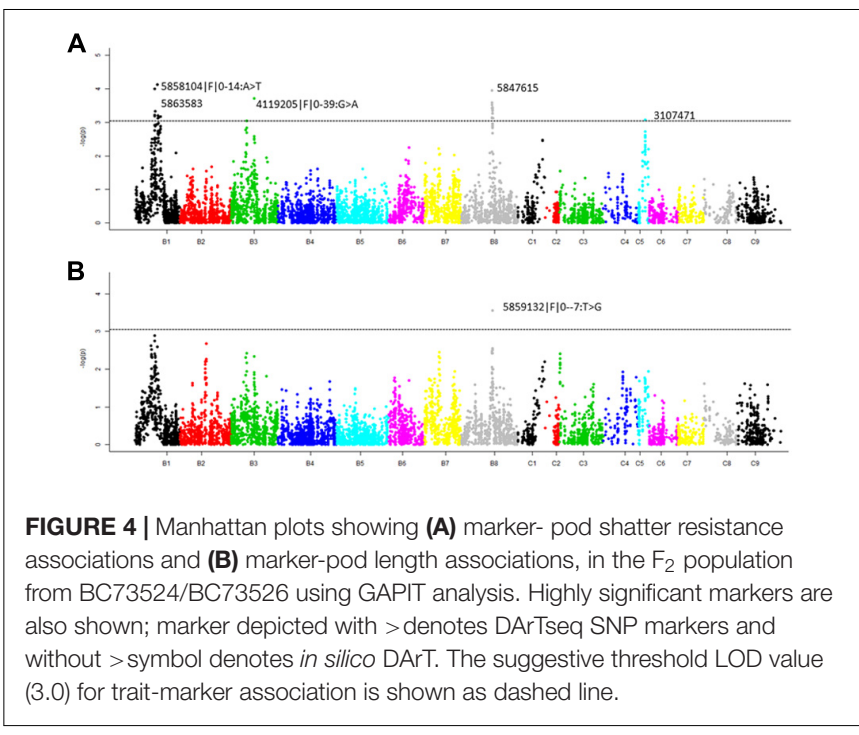

be harnessed for further genetic improvement of $B$. carinata as well as other Brassica species.

We determined the pod strength (RE) in B. carinata with pendulum test, as a proxy for shatter resistance. This method was found to be reliable and repeatable in determining the extent of pod-shatter resistance and mapping QTL in B. carinata (this study, Table 3 and Supplementary Table S4). Similar findings were made in previous studies on genetic variation for pod shatter resistance in B. rapa and B. napus (Kadkol et al., 1985, 1986b; Prakash and Chopra, 1988; Mongkolporn et al., 2003; Wang et al., 2007; Raman H. et al., 2014; Zhang et al., 2016). We revealed that pod shatter resistance is due to multiple genes in the $\mathrm{F}_{2}$ population of B. carinata derived from the BC73524/BC73526. Multigenic inheritance for pod shatter resistance in $B$. carinata (this study) is consistent with previous findings in $B$. rapa and B. napus (Mongkolporn et al., 2003; Wen et al., 2013; Raman H. et al., 2014; Liu et al., 2016).

In this study, a linkage map of a $\mathrm{F}_{2}$ population was constructed utilizing 6,464 DArTseq markers and subsequently used for QTL analysis. The marker density of this linkage map (Table 2) was comparable with the linkage map of a DH population of B. carinata derived from YW (Zou et al., 2014). The majority of DArTseq markers were linked with the physical positions on the reference genomes of B. nigra/B. juncea and B. oleracea/B. napus. In addition, several scaffolds which were unassembled in the reference B. juncea sequence (Yang et al., 2016) could be mapped to the linkage map of $B$. carinata population (Supplementary Table S1). Our results suggested that the reference genomes are useful in anchoring different linkage groups to pseudomolecules and facilitating molecular marker and candidate gene discovery. One of the QTL, Qpsr.wwai-B1a delimited with marker 5834957 was mapped to the B1 pseudomolecule of B. nigra within 63.12 $\mathrm{kb}$ of Arabidopsis FUL ortholog (Supplementary Table S4). Ostergaard et al. (2006) showed that ectopic expression of the Arabidopsis FUL gene in B. juncea is sufficient to produce pod shatter resistance, via negative regulation of the valvemargin identity genes (Ferrandiz et al., 2000). However, the 

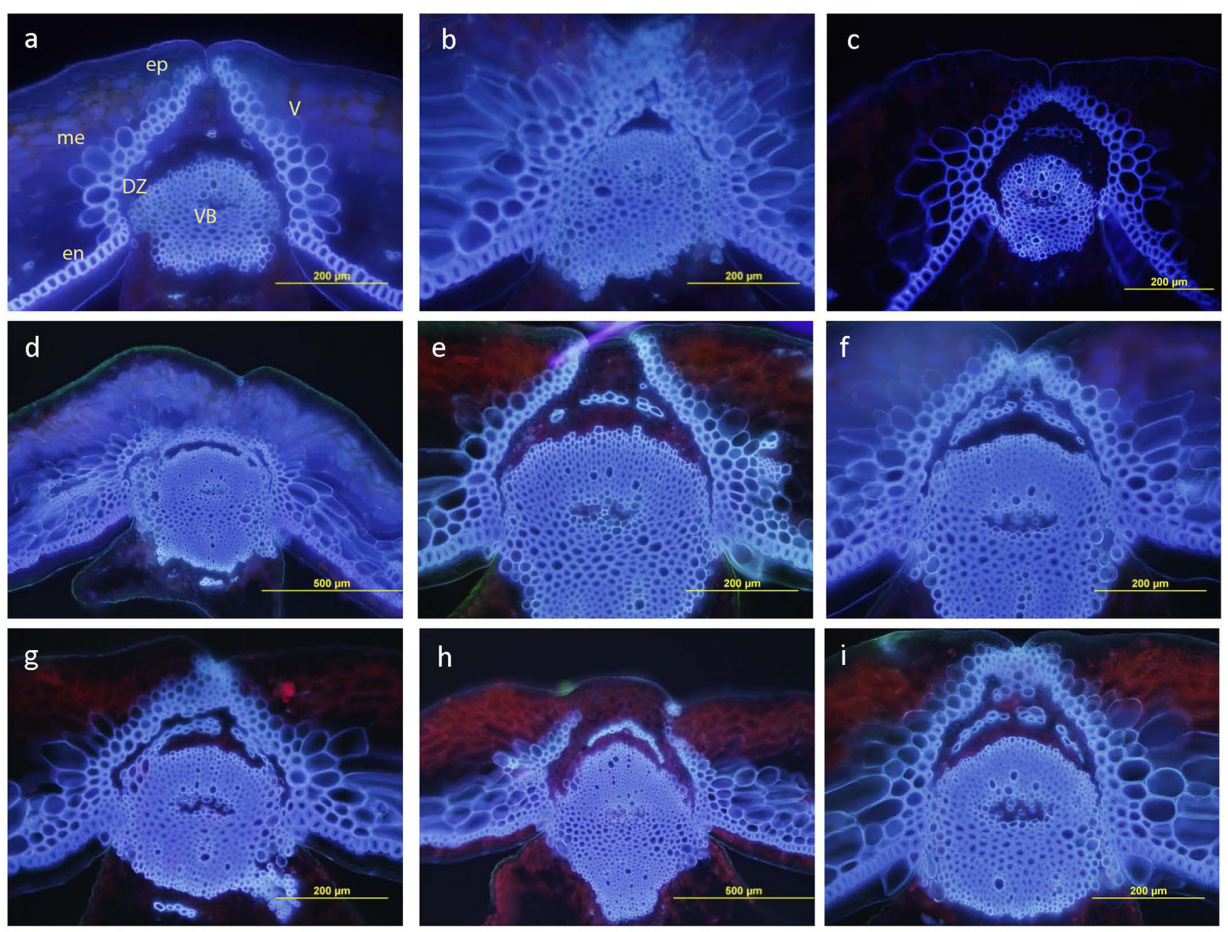

FIGURE 5 | Anatomical features of dehiscence zone also called abscission layer in parents and $\mathrm{F}_{2}$ plants of the BC73524/BC73526. (a) BC73524, (b) BC73526, (c) B. napus advanced breeding line, BLN2762 and (d-i) $F_{2}$ plants with varying level of dehiscence zone development. Transverse pod section of BC73524 showing well-developed DZ whereas BC73526 showing almost no DZ differentiation. V: valve, VB: vascular bundle of ruplum, en: endocarp, ep: epicarp, me: mesocarp.

transgenic B. juncea fruit produced were too tightly closed. Similar observations were made in this study, the shatter resistant accession BC73526 did not dehisce under natural field conditions and there was no clear separation between valve margin and replum (Figure 5). A close link between pod shatter resistance and DZ differentiation was observed, the shatter prone and shatter tolerant accessions could be differentiated based on pod anatomy. The shatter prone accession (BC73524) had a welldeveloped DZ as compared with shatter resistant (BC73526). Similar observations have been made in A. thaliana, B. rapa, B. napus, and B. carinata (Kadkol et al., 1986a; Jenkins et al., 1999; Ferrandiz et al., 2000; Sorefan et al., 2009; Raman H. et al., 2014). Several genes; FUL, SHP1, SHP2, ALC, IND, and RPL have been implicated in the development of the valve-margin separation layer, and lignification of the endocarp layer (Dinneny and Yanofsky, 2005). Girin et al. (2010) showed that homozygous braA.ind.a mutants showed a clear loss of valve margin formation in B. rapa and B. oleracea.

The marker 5834957 at Qpsr.wwai-B1a also showed the complete linkage with other loci; 5861424, 5832583, 5843024, 5854441, 5842255, 5843155, and 5849931. These markers were mapped at the $49.81 \mathrm{cM}$ of the $\mathrm{F}_{2}$ map and showed significant sequence identities with the A09 reference genome sequence of $B$. juncea (coordinates $6,440,430$ to $7,118,167$ CM007193.1_chromosome_A9, coordinate 6480570bp, 1.84E25) (Supplementary Table S1). In previous studies, a major QTL for pod shatter resistance was located on chromosomes A09/C08, in the vicinity of SHATTERPROOF gene in B. napus populations (Hu et al., 2012; Raman H. et al., 2014; Liu et al., 2016). We searched the SHP1 and SHP2 orthologs in the reference genome of B. juncea. One of the SHP1 homologs was mapped $\sim 35$ $\mathrm{Mb}$ away from the highly significant SNP marker 5834957 on pseudomolecule A09 of B. juncea [sequence identity $=323$ bits (163), Expect $=3 \mathrm{e}-86,211 / 227$ (92\%); coordinates 45,984,225 to 45983999 (Supplementary Table S4)]. While, one of the six SHP2a (JQ973082.1 B. napus SHATTERPROOF mRNA) homologs was located in the vicinity of the highly significant SNP marker 5834957 on chromosome B1/A09 [313 bits, score: 2e83 , Identities $=176 / 182(96 \%)$ ]. In addition to SHP2 and FUL, other genes controlling pod shatter resistance such as IND were also mapped near the statistical significant marker associations (Table 3), suggesting the markers identified for pod shatter resistance herein are reliable.

\section{CONCLUSION}

We mapped QTL controlling pod shatter resistance in B. carinata and identified sequence-based molecular markers. These traitmarker associations with respect to reference genomes of $B$. napus, and B. juncea could also pave the way for delineation of pod shatter resistance QTL involved in natural variation, map-based cloning of those QTL and unravel the molecular architecture of pod shatter resistance genes in natural germplasm of $B$. carinata. In addition, molecular markers identified herein 
will enable us to trace the introgression of pod shatter resistance alleles for strategic improvement of B. carinata, B. napus, and other related species. Previous studies have reported that there is limited genetic variation for pod shatter resistance in the natural B. napus germplasm (Bowman, 1984; Raman H. et al., 2014). Several research groups around the world are currently using B. carinata to expand the narrow genetic base of $B$. napus germplasm (Cowling, 2007; Dhaliwal et al., 2017). In this study, only one QTL, Qpsr.wwai-C5 was identified on the C subgenome of $B$. carinata (chromosome C05), while other QTL were identified on the B subgenome (B1, B3, and B8). Previous studies have shown that fertile plants of $B$. napus carrying $\mathrm{B}$ genome introgressions can be generated (Navabi et al., 2010; Dhaliwal et al., 2017). It remains to be established whether B and $C$ genome derived lines exhibit pod shatter resistance expression or get silenced in the resynthesized B. napus (Xu et al., 2009). Nevertheless, our results provide valuable information on donor sources for pod shatter resistance, genetic inheritance, genetic map location of QTL, and associated markers for marker-assisted selection. The markers identified in this study can be assayed on any sequencing platform and/or converted into simple KASP assay for high throughput analysis.

\section{AUTHOR CONTRIBUTIONS}

RR and HR designed the study, and prepared the manuscript. RR developed $F_{2}$ and $F_{3}$ populations, conducted the experiments and analyzed the data. NC designed the field trials and RR and NC analyzed the data, YQ assisted in phenotyping, performed pod

\section{REFERENCES}

Altschul, S., Gish, W., Miller, W., Myers, E., and Lipman, D. (1990). Basic local alignment search tool. J. Mol. Biol. 215, 403-410. doi: 10.1016/S0022-2836(05) 80360- 2

Applegate, D. L., Bixby, R. E., Chvátal, V., and Cook, W. J. (2006). The Traveling Salesman Problem. Princeton Series in Applied Mathematics. Princeton, NJ: Princeton University Press.

Arnaud, N., Girin, T., Sorefan, K., Fuentes, S., Wood, T. A., Lawrenson, T., et al. (2010). Gibberellins control fruit patterning in Arabidopsis thaliana. Genes Dev. 24, 2127-2132. doi: 10.1101/gad.593410

Banga, S., Kaur, G., Grewal, N., Salisbury, P. A., and Banga, S. S. (2011). “Transfer of resistance to seed shattering from Brassica carinata to B. napus," in Proceedings of the 13th International Rapeseed Congress, Prague, 863-865.

Bowman, J. G. (1984). Commercial oilseed rape breeding. Aspects Appl. Biol. 6, 31-36.

Chandler, J., Corbesier, L., Spielmann, P., Dettendorfer, J., Stahl, D., Apel, K., et al. (2005). Modulating flowering time and prevention of pod shatter in oilseed rape. Mol. Breed. 15, 87-94. doi: 10.1007/s11032-004-2735-4

Clarke, K. R., and Gorley, R. N. (2006). PRIMER v6: User Manual/Tutorial. Plymouth: PRIMER-E Ltd.

Colton, B., and Potter, T. (eds). (1999). "History," in Canola in Australia: the First Thirty Years (Canberra, ACT: Organising Committee of the 10th International Rapeseed Congress).

Cowling, W. A. (2007). Genetic diversity in Australian canola and implications for crop breeding for changing future environments. Field Crops Res. 104, 103-111. doi: 10.1016/j.fcr.2006.12.014

Dhaliwal, I., Mason, A. S., Banga, S., Bharti, S., Kaur, B., Gurung, A. M., et al. (2017). Cytogenetic and molecular characterization of B-genome introgression lines of Brassica napus L. G3 7, 77-86. doi: 10.1534/g3.116.036442 anatomy, and DNA extractions. AK and JS aligned DArTseq data with the reference genomes. All authors reviewed and edited the manuscript.

\section{FUNDING}

We thank the Grains Research and Development Corporation and NSW DPI for the investment made to support this research under the project, DAN00208.

\section{ACKNOWLEDGMENT}

Authors thank Dr. Bob Redden, Australian Grains Genebank, Horsham, Australia for providing the B. carinata accessions, Ms. Louisa Slinger and Mr. John Bromfield for pendulum testing.

\section{SUPPLEMENTARY MATERIAL}

The Supplementary Material for this article can be found online at: https://www.frontiersin.org/articles/10.3389/fpls.2017.01765/ full\#supplementary-material

FIGURE S1 | Analysis of the population structure of 83 B. carinata accessions. The likelihood values $[\mathrm{Ln}(\mathrm{P}(\mathrm{D}]$ for each successive $\mathrm{K}$.

FIGURE S2 | Manhattan plots showing marker-pod shatter resistance associations in the $F_{2}$ population using the SVS package. A linear markers regression analysis was performed to identify loci associated with pod rupture energy.

Dinneny, J. R., and Yanofsky, M. F. (2005). Drawing lines and borders: how the dehiscent fruit of Arabidopsis is patterned. Bioessays 27, 42-49. doi: 10.1002/ bies. 20165

Enjalbert, J. N., Zheng, S., Johnson, J. J., Mullen, J. L., Byrne, P. F., and McKay, J. K. (2013). Brassicaceae germplasm diversity for agronomic and seed quality traits under drought stress. Ind. Crops Prod. 47, 176-185. doi: 10.1016/j.indcrop.2013. 02.037

Evanno, G., Regnaut, S., and Goudet, J. (2005). Detecting the number of clusters of individuals using the software STRUCTURE: a simulation study. Mol. Ecol. 14, 2611-2620. doi: 10.1111/j.1365-294X.2005.02553.x

Ferrandiz, C., Liljegren, S. J., and Yanofsky, M. F. (2000). Negative regulation of the SHATTERPROOF genes by FRUITFULL during Arabidopsis fruit development. Science 289, 436-438. doi: 10.1126/science.289.5478.436

Getinet, A., Rakow, G., and Downey, R. K. (1996). Agronomic performance and seed quality of Ethiopian mustard in Saskatchewan. Can. J. Plant Sci. 76, 387-392. doi: 10.4141/cjps96-069

Girin, T., Stephenson, P., Goldsack, C. M. P., Kempin, S. A., Perez, A., Pires, N., et al. (2010). Brassicaceae INDEHISCENT genes specify valve margin cell fate and repress replum formation. Plant J. 63, 329-338. doi: 10.1111/j.1365-313X. 2010.04244.x

Guo, S., Zou, J., Li, R., Long, Y., Chen, S., and Meng, J. (2012). A genetic linkage map of Brassica carinata constructed with a doubled haploid population. Theor. Appl. Genet. 125, 1113-1124. doi: 10.1007/s00122-012-1898-3

Hossain, S., Kadkol, G., Raman, R., Salisbury, P., and Raman, H. (2011). "Breeding Brassica napus for shatter resistance," in Plant Breeding, ed. I. Y. Abdurakhmonov (Rijeka: InTech).

Hu, Z., Hua, W., Huang, S., Yang, H., Zhan, G., Wang, X., et al. (2012). Discovery of pod shatter-resistant associated SNPs by deep sequencing of a representative library followed by bulk segregant analysis in rapeseed. PLOS ONE 7:e34253. doi: 10.1371/journal.pone.0034253 
Jenkins, E. S., Paul, W., Craze, M., Whitelaw, C. A., Weigand, A., and Roberts, J. A. (1999). Dehiscence-related expression of an Arabidopsis thaliana gene encoding a polygalacturonase in transgenic plants of Brassica napus. Plant Cell Environ. 22, 159-167. doi: 10.1046/j.1365-3040.1999.00372.x

Jiang, Y., Tian, E., Li, R., Chen, L., and Meng, J. (2007). Genetic diversity of Brassica carinata with emphasis on the interspecific crossability with B. rapa. Plant Breed. 126, 487-491. doi: 10.1111/j.1439-0523.2007.01393.x

Kadkol, G., Halloran, G., and Macmillan, R. (1985). Evaluation of Brassica genotypes for resistance to shatter. II. Variation in siliqua strength within and between accessions. Euphytica 34, 915-924. doi: 10.1007/BF00035431

Kadkol, G. P., Beilharz, V. C., Halloran, G. M., and Macmillan, R. H. (1986a). Anatomical basis of shatter-resistance in the oilseed Brassicas. Aust. J. Bot. 34, 595-601. doi: 10.1071/BT9860595

Kadkol, G. P., Halloran, G. M., and MacMillan, R. H. (1986b). Inheritance of siliqua strength in Brassica campestris L. I. Studies of $\mathrm{F}_{2}$ and backcross populations. Can. J. Genet. Cytol. 28, 365-373. doi: 10.1139/g86-054

Liljegren, S. J., Leslie, M. E., Darnielle, L., Lewis, M. W., Taylor, S. M., Luo, R. B., et al. (2009). Regulation of membrane trafficking and organ separation by the NEVERSHED ARF-GAP protein. Development 136, 1909-1918. doi: 10.1242/ dev.033605

Liljegren, S. J., Roeder, A. H., Kempin, S. A., Gremski, K., Østergaard, L., Guimil, S., et al. (2004). Control of fruit patterning in Arabidopsis by INDEHISCENT. Cell 116, 843-853. doi: 10.1016/S0092-8674(04)00217-X

Lipka, A. E., Tian, F., Wang, Q., Peiffer, J., Li, M., Bradbury, P. J., et al. (2012). GAPIT: genome association and prediction integrated tool. Bioinformatics 28, 2397-2399. doi: 10.1093/bioinformatics/bts444

Liu, J., Wang, J., Wang, H., Wang, W., Zhou, R., Mei, D., et al. (2016). Multigenic control of pod shattering resistance in Chinese rapeseed germplasm revealed by genome-wide association and linkage analyses. Front. Plant Sci. 7:1058. doi: $10.3389 /$ fpls. 2016.01058

Liu, X. Y., Macmillan, R. H., Burrow, R. P., Kadkol, G. P., and Halloran, G. M. (1994). Pendulum test for evaluation of rupture strength of seed pods. J. Texture Stud. 25, 179-189. doi: 10.1111/j.1745-4603.1994.tb01325.x

Malik, R. S. (2008). Prospects for Brassica carinata as an Oilseed crop in India. Exp. Agric. 26, 125-129. doi: 10.1017/S0014479700015465

Mongkolporn, O., Kadkol, G. P., Pang, C. K., and Taylor, P. W. J. (2003). Identification of RAPD markers linked to recessive genes conferring siliqua shatter resistance in Brassica rapa. Plant Breed. 122, 479-484. doi: 10.1046/j. 0179-9541.2003.00910.x

Navabi, Z. K., Parkin, I. A., Pires, J. C., Xiong, Z., Thiagarajah, M. R., and Good, A. G. (2010). Introgression of B-genome chromosomes in a doubled haploid population of Brassica napus x B. carinata. Genome 53, 619-629. doi: 10.1139/ G10-039

Ostergaard, L., Kempin, S. A., Bies, D., Klee, H. J., and Yanofsky, M. F. (2006). Pod shatter-resistant Brassica fruit produced by ectopic expression of the FRUITFULL gene. Plant Biotechnol. J. 4, 45-51. doi: 10.1111/j.1467-7652.2005. 00156.x

Petroli, C. D., Sansaloni, C. P., Carling, J., Steane, D. A., Vaillancourt, R. E., Myburg, A. A., et al. (2012). Genomic characterization of DArT markers based on highdensity linkage analysis and physical mapping to the eucalyptus genome. PLOS ONE 7:e44684. doi: 10.1371/journal.pone.0044684

Prakash, S., and Chopra, V. L. (1988). Introgression of resistance to shattering in Brassica napus from Brassica juncea through non-homologous recombination. Plant Breed. 101, 167-168. doi: 10.1111/j.1439-0523.1988.tb00283.x

Price, A. L. (2006). Principal components analysis corrects for stratification in genome-wide association studies. Nat. Genet. 38, 904-909. doi: 10.1038/ng1847

Pritchard, J. K., Matthew, S., and Donnelly, P. (2000). Inference of population structure using multilocus genotype data. Genetics 155, 945-959.

Rajani, S., and Sundaresan, V. (2001). The Arabidopsis myc/bHLH gene ALCATRAZ enables cell separation in fruit dehiscence. Curr. Biol. 11, 19141922. doi: 10.1016/S0960-9822(01)00593-0

Raman, H., Raman, R., Kilian, A., Detering, F., Carling, J., Coombes, N., et al. (2014). Genome-wide delineation of natural variation for pod shatter resistance in Brassica napus. PLOS ONE 9:e101673. doi: 10.1371/journal.pone.0101673

Raman, R., Coombes, N., Qiu, Y., Burrows, G., Kilian, A., and Raman, H. (2014). "Accessing natural genetic variation for pod shatter resistance in Brassica species," in Proceedings of the 18th Australian Research Assembly on Brassicas, 29th September-2nd October 2014, Tanunda, SA.

Raman, R., Raman, H., Johnstone, K., Lisle, C., Smith, A., Martin, P., et al. (2005). Genetic and in silico comparative mapping of the polyphenol oxidase gene in bread wheat (Triticum aestivum L.). Funct. Integr. Genomics 5, 185-200. doi: 10.1007/s10142-005-0144-3

Roeder, A. H. K., Ferrándiz, C., and Yanofsky, M. F. (2003). The role of the REPLUMLESS homeodomain protein in patterning the Arabidopsis fruit. Curr. Biol. 13, 1630-1635. doi: 10.1016/j.cub.2003.08.027

Rosenberg, N. A., Burke, T., Elo, K., Feldman, M. W., Freidlin, P. J., Groenen, M. A., et al. (2001). Empirical evaluation of genetic clustering methods using multilocus genotypes from 20 chicken breeds. Genetics 159, 699-713.

Sharma, B. B., Kalia, P., Singh, D., and Sharma, T. R. (2017). Introgression of black rot resistance from Brassica carinata to cauliflower (Brassica oleracea botrytis group) through embryo rescue. Front. Plant Sci. 8:1255. doi: 10.3389/fpls.2017. 01255

Sorefan, K., Girin, T., Liljegren, S. J., Ljung, K., Robles, P., Galvan-Ampudia, C. S., et al. (2009). A regulated auxin minimum is required for seed dispersal in Arabidopsis. Nature 459, 583-586. doi: 10.1038/nature07875

Taylor, I. D., Conway, S., Roberts, S. J., Astley, D., and Vicente, I. G. (2002). Sources and origin of resistance to Xanthomonas campestris pv. campestris in Brassica genomes. Phytopathology 92, 105-111. doi: 10.1094/PHYTO.200292.1.105

Tian, E. T., Jiang, Y. F., Chen, L. L., Zou, J., Liu, F., and Meng, J. L. (2010). Synthesis of a Brassica trigenomic allohexaploid (B. carinata x B. rapa) de novo and its stability in subsequent generations. Theor. Appl. Genet. 121, 1431-1440. doi: 10.1007/s00122-010-1399-1

Wang, R., Ripley, V. L., and Rakow, G. (2007). Pod shatter resistance evaluation in cultivars and breeding lines of Brassica napus, B. juncea and Sinapis alba. Plant Breed. 126, 588-595. doi: 10.1111/j.1439-0523.2007.01382.x

Warwick, S. I., Gugel, R. K., McDonald, T., and Falk, K. C. (2006). Genetic variation of Ethiopian mustard (Brassica carinata A. Braun) germplasm in western Canada. Genet. Resour. Crop Evol. 253, 297-312. doi: 10.1007/s10722004-6108-y

Wei, Z., Wang, M., Chang, S., Wu, C., Liu, P., Meng, J., et al. (2016). Introgressing subgenome components from Brassica rapa and B. carinata to B. juncea for broadening its genetic base and exploring intersubgenomic heterosis. Front. Plant Sci. 7:1677. doi: 10.3389/fpls.2016.01677

Wen, Y. C., Zhang, S. F., Yi, B., Wen, J., Wang, J. P., Zhu, J. C., et al. (2013). Identification of QTLs involved in pod-shatter resistance in Brassica napus L. Crop Pasture Sci. 63, 1082-1089. doi: 10.1071/CP12318

$\mathrm{Wu}$, Y., Bhat, P. R., Close, T. J., and Lonardi, S. (2008). Efficient and accurate construction of genetic linkage maps from the minimum spanning tree of a graph. PLOS Genet. 4:e1000212. doi: 10.1371/journal.pgen.1000212

Xu, Y., Zhong, L., Wu, X., Fang, X., and Wang, J. (2009). Rapid alterations of gene expression and cytosine methylation in newly synthesized Brassica napus allopolyploids. Planta 229, 471-483. doi: 10.1007/s00425-008-0844-8

Yang, J., Liu, D., Wang, X., Ji, C., Cheng, F., Liu, B., et al. (2016). The genome sequence of allopolyploid Brassica juncea and analysis of differential homoeolog gene expression influencing selection. Nat. Genet. 48, 1225-1232. doi: 10.1038/ ng.3657

Yu, J., Pressoir, G., Briggs, W. H., Bi, I. V., Yamasaki, M., Doebley, J. F., et al. (2006). A unified mixed-model method for association mapping that accounts for multiple levels of relatedness. Nat. Genet. 38, 203-208. doi: 10.1038/ ng1702

Zhang, Y., Shen, Y. Y., Wu, X. M., and Wang, J. B. (2016). The basis of pod dehiscence: anatomical traits of the dehiscence zone and expression of eight pod shatter-related genes in four species of Brassicaceae. Biol. Plant. 60, 343-354. doi: 10.1007/s10535-016-0599-1

Zou, J., Raman, H., Guo, S., Hu, D., Wei, Z., Luo, Z., et al. (2014). Constructing a dense genetic linkage map and mapping QTL for the traits of flower development in Brassica carinata. Theor. Appl. Genet. 127, 1593-1605. doi: $10.1007 / \mathrm{s} 00122-014-2321-\mathrm{z}$

Conflict of Interest Statement: AK is the director of Diversity Arrays Technology Pty Ltd. and JS was employed by Diversity Arrays Technology Pty Ltd. All other authors declare no competing interests.

Copyright (c) 2017 Raman, Qiu, Coombes, Song, Kilian and Raman. This is an open-access article distributed under the terms of the Creative Commons Attribution License (CC BY). The use, distribution or reproduction in other forums is permitted, provided the original author(s) or licensor are credited and that the original publication in this journal is cited, in accordance with accepted academic practice. No use, distribution or reproduction is permitted which does not comply with these terms. 